\title{
BMJ
}

\section{Prostate specific antigen concentration at age 60 and death or metastasis from prostate cancer: case-control study}

\author{
Andrew J Vickers, associate attending research methodologist, ${ }^{1}$ Angel M Cronin, research biostatistician, ${ }^{1}$ \\ Thomas Björk, senior consultant, ${ }^{2}$ Jonas Manjer, associate professor, ${ }^{2}$ Peter M Nilsson, professor, ${ }^{2}$ Anders \\ Dahlin, data manager, ${ }^{2}$ Anders Bjartell, professor, ${ }^{2}$ Peter T Scardino, department chair, ${ }^{3}$ David Ulmert, \\ research fellow/resident, ${ }^{4,5}$ Hans Lilja, attending research clinical chemist/professor (adjunct) ${ }^{6,7}$
}

${ }^{1}$ Department of Epidemiology and Biostatistics, Memorial SloanKettering Cancer Center, New York, NY 10065, USA

${ }^{2}$ Department of Clinical Sciences (Urological Cancers, Medicine, Surgery), Lund University, University Hospital in Malmo, 205 02, Malmo, Sweden

${ }^{3}$ Department of Surgery, Memorial Sloan-Kettering Cancer Center, New York

${ }^{4}$ Department of Surgery (Urology) Memorial Sloan-Kettering Cancer Center, New York

${ }^{5}$ Departments of Clinical Sciences and Laboratory Medicine, Lund University, Skane University Hospital, 20502 Malmo

${ }^{6}$ Department of Clinical Laboratories, Surgery and Medicine, Memorial Sloan Kettering Cancer Center, New York

${ }^{7}$ Department of Laboratory Medicine, Lund University, Skane University Hospital, 20502 Malmo

Correspondence to: $\mathrm{H}$ Lilja, Department of Clinical Laboratories, Surgery and Medicine, Memorial Sloan Kettering Cancer Center, New York, NY 10065, USA liljah@mskcc.org

Cite this as: BMJ 2010;341:C4521 doi:10.1136/bmj.c4521

\section{ABSTRACT}

Objective To determine the relation between concentrations of prostate specific antigen at age 60 and subsequent diagnosis of clinically relevant prostate cancer in an unscreened population to evaluate whether screening for prostate cancer and chemoprevention could be stratified by risk.

Design Case-control study with 1:3 matching nested within a highly representative population based cohort study.

Setting General population of Sweden taking part in the Malmo Preventive Project. Cancer registry at the National Board of Health and Welfare.

Participants 1167 men aged 60 who provided blood samples in 1981 and were followed up to age 85 .

Main outcome measures Metastasis or death from prostate cancer.

Results The rate of screening during the course of the study was low. There were 43 cases of metastasis and 35 deaths from prostate cancer. Concentration of prostate specific antigen at age 60 was associated with prostate cancer metastasis (area under the curve 0.86, 95\% confidence interval 0.79 to $0.92 ; \mathrm{P}<0.001)$ and death from prostate cancer $(0.90,0.84$ to 0.96 ; $\mathrm{P}<0.001)$. The greater the number for the area under the curve (values from 0 to 1) the better the test. Although only a minority of the men with concentrations in the top quarter $(>2 \mathrm{ng} / \mathrm{ml})$ develop fatal prostate cancer, $90 \%$ (78\% to $100 \%$ ) of deaths from prostate cancer occurred in these men. Conversely, men aged 60 with concentrations at the median or lower $(\leq 1$ $\mathrm{ng} / \mathrm{ml}$ ) were unlikely to have clinically relevant prostate cancer $(0.5 \%$ risk of metastasis by age 85 and $0.2 \%$ risk of death from prostate cancer).

Conclusions The concentration of prostate specific antigen at age 60 predicts lifetime risk of metastasis and death from prostate cancer. Though men aged 60 with concentrations below the median $(\leq 1 \mathrm{ng} / \mathrm{ml})$ might harbour prostate cancer, it is unlikely to become life threatening. Such men could be exempted from further screening, which should instead focus on men with higher concentrations.

\section{INTRODUCTION}

Testing for prostate specific antigen is widely used for the early detection of prostate cancer. Even before randomised evidence as to the effects of screening on mortality became available, ${ }^{12}$ about half of age appropriate men in the United States presented for regular tests. ${ }^{3}$

The operating characteristics of the prostate specific antigen test have been determined by comparing concentrations with the result of prostate biopsy. ${ }^{4-6} \mathrm{~A}$ notable feature of such studies is that men with concentrations below commonly used biopsy thresholds, such as $4 \mathrm{ng} / \mathrm{ml}$, have a substantial risk of cancer detectable at biopsy. ${ }^{7}$ Yet it has been established from autopsy studies that many men dying of causes other than prostate cancer none the less harbour prostate tumours. A typical estimate is that close to $40 \%$ of 70 year old men have detectable cancer in the prostate at autopsy. ${ }^{8}$ This figure is reflected in the widely recognised problem of overdiagnosis, ${ }^{910}$ with the European randomised trial suggesting that 48 men with screen detected cancer need to be treated for one death from prostate cancer to be avoided at nine years. ${ }^{2}$

Accordingly, the key question is not whether a man has prostate cancer but whether that cancer is likely to cause symptoms or shorten his life. In 1981-2, a highly representative cohort of 60 year old Swedish men provided blood samples for cardiovascular studies as part of the Malmo Preventive Project. ${ }^{112}$ We have been able to match these samples to cancer registries updated on 31 December 2006, when participants had either died or reached their 85th birthday. The rate of prostate specific antigen screening in Sweden during this time was low, ${ }^{13}$ and men in this cohort would have been too old to be eligible for screening by the time the screening test became available in Sweden in the 1990s. As such, the study provides a natural experiment to determine the association between prostate specific antigen concentrations, taken at an age typical for a man undergoing screening, and lifetime risk of clinically detected prostate cancer, prostate cancer metastasis, and death from prostate cancer. 


\section{METHODS}

\section{Study participants}

The Malmo Preventive Project has been previously described. ${ }^{112}$ The cohort reported here includes 1167 men born in 1921, constituting $71 \%$ of the eligible population, who gave blood and completed medical history and lifestyle questionnaires in 1981-2. Records of participants were linked to the cancer registry at the National Board of Health and Welfare in Sweden to identify men diagnosed with prostate cancer up to 31 December 2006. This registry has been shown to be highly accurate. ${ }^{14}$ We excluded five men diagnosed with prostate cancer before the date of their baseline blood sample. Medical charts were available for 101 of 126 men $(80 \%)$ with a diagnosis of prostate cancer, including 73 of 88 men (83\%) who subsequently died. One urologist (DU), blinded to baseline prostate specific antigen data, reviewed charts, which were also independently reviewed for cause of death (by TB). When medical charts were not available, data on metastasis were taken from National Cancer Registry data on stage at diagnosis (14 patients, six with metastasis); cause of death was obtained from the Causes of Death Registry at the National Board of Health and Welfare in Sweden ( $\mathrm{n}=15$, six deaths from prostate cancer).

We used a nested case-control design to analyse data from the cohort. Separate matches were conducted for each of the three study events: clinically diagnosed prostate cancer, prostate cancer metastasis, and death from prostate cancer. A metastasis event included metastases documented at the time of diagnosis of prostate cancer as well as those metastases documented subsequently. Men who died from prostate cancer without previous clinical documentation of metastasis were defined as having been diagnosed with metastasis at the date of death. For each end point, we selected three controls at random from the group of men alive and event-free at the time of the event in the affected patient (the case) during follow-up. Controls were matched on date of birth and date of baseline blood

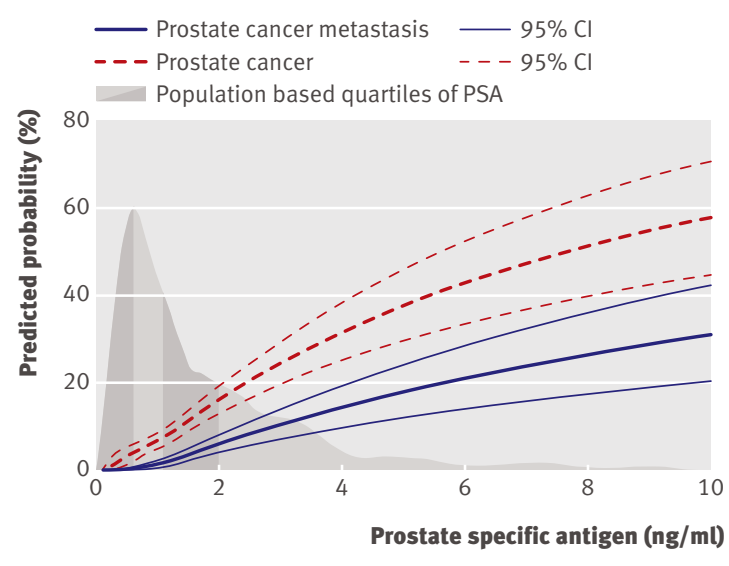

Fig 1 | Lifetime risk of clinically diagnosed prostate cancer or prostate cancer metastasis. Shaded region represents population based distribution of prostate specific antigen. Curves for risk of death from prostate cancer nearly overlap with curves for prostate cancer metastasis and are not shown
Table 1|Characteristics of entire study cohort $(n=1162)$ at 31 December 2006. Figures are numbers (percentages) unless stated otherwise

\begin{tabular}{lc}
$\begin{array}{l}\text { Alive at age 85: } \\
\text { Without prostate cancer }\end{array}$ & Data \\
\hline With non-metastatic prostate cancer & $38(31)$ \\
\hline With metastatic prostate cancer & $0(0)$ \\
\hline Died from other causes: & $668(57)$ \\
\hline Without prostate cancer & $45(4)$ \\
\hline With non-metastatic prostate cancer & $35(1)$ \\
\hline With metastatic prostate cancer & $8(1)$ \\
\hline Died from prostate cancer & $1.06(0.65-1.92)$ \\
\hline Emigrated & \\
\hline Median (IQR) PSA at age 60 (ng/ml)* & \\
\hline IQR=interquartile range; PSA=prostate specific antigen. \\
*Imputed to whole population from case-control data.
\end{tabular}

sample, with a window of three months. Using this algorithm, we successfully matched three controls to each case for all of the study end points.

\section{Laboratory methods}

Total prostate specific antigen was assayed in anticoagulated blood plasma stored at $-20^{\circ} \mathrm{C}$ for up to 27 years. We have shown that prostate specific antigen is not significantly labile when stored under these conditions. ${ }^{15}$ Levels of total prostate specific antigen (plus free prostate specific antigen and kallikrein related peptidase 2 (hK2)) were determined as previously reported ${ }^{1617}$ and conducted in accordance with World Health Organization calibration standards at Lund University.

\section{Statistical methods}

We used conditional logistic regression to test the association between prostate specific antigen concentrations and study end points. The area under the receiver operating characteristic curve was calculated directly from the concentrations, with confidence intervals obtained by the method of Delong et al. ${ }^{18}$ The area under the curve is a simple quantitative summary value of whether the continuous measure (in this case prostate specific antigen) is a good diagnostic tool. Values can lie between 0.5 and 1 , with higher values showing greater diagnostic power. All statistical analyses were conducted with Stata 10.1 (StataCorp LP, College Station, TX).

To estimate the risk of the prostate cancer outcomes for a given concentration, we used locally weighted scatterplot smoothing (LOWESS) ${ }^{19}$ to allow for a non-linear relation between prostate specific antigen and outcome. To obtain population based estimates of risk, we first imputed concentrations for participants without measured prostate specific antigen -623 men without a diagnosis of prostate cancer who were not selected as controls - by randomly sampling concentrations with replacement from cancer-free controls. We then used LOWESS to estimate risk; the imputation and estimation was repeated 200 times, with the 


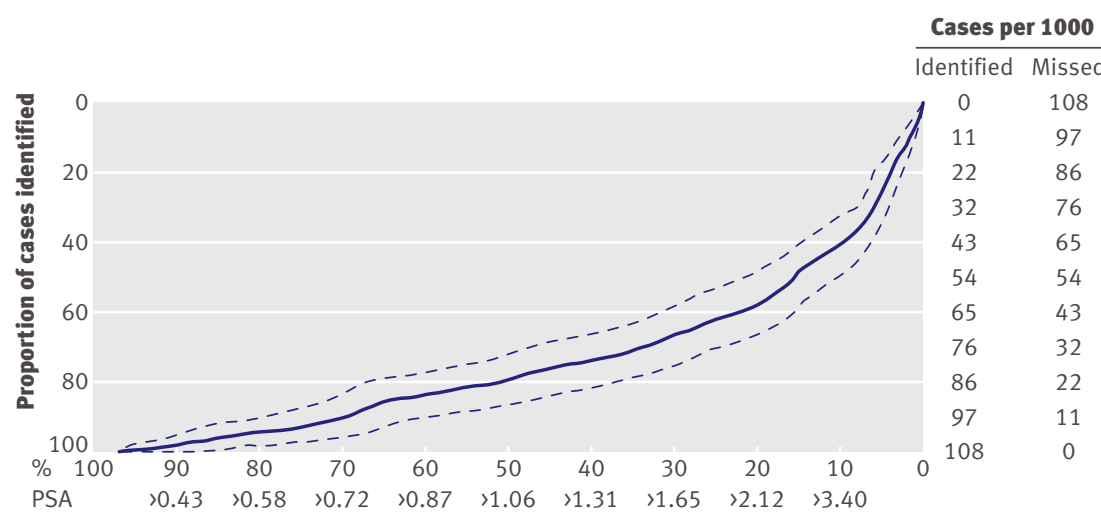

Proportion of population classified as high risk

Fig 2 | Lorenz curve for clinically detected prostate cancer: $x$ axis shows percentage of population with prostate specific antigen (PSA) above indicated concentrations, hence percentages run from 100 down to 0 ; y axis shows number of events that would be included (or missed) if we consider only men with prostate specific antigen above any given concentration

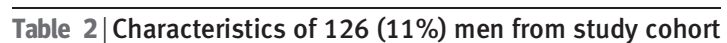
with diagnosis of prostate cancer. Figures are numbers (percentages) unless stated otherwise

\begin{tabular}{lc}
\multicolumn{1}{l}{ Clinical T stage: } & \\
\hline T1 & $33(26)$ \\
\hline T2 & $45(36)$ \\
\hline T3/T4 & $37(29)$ \\
\hline Unknown & $11(9)$ \\
\hline Clinical N stage: & $9(7)$ \\
\hline N0 & $3(2)$ \\
\hline NX & $114(90)$ \\
\hline
\end{tabular}

Clinical M stage:

\begin{tabular}{ll}
\hline M0 & $57(45)$ \\
\hline M1 & $13(10)$ \\
\hline MX & $56(44)$ \\
\hline
\end{tabular}

Biopsy grade:

\begin{tabular}{lc}
\hline WHO I or Gleason $\leq 5$ & $29(23)$ \\
\hline WHO II or Gleason 6 or 7 & $53(42)$ \\
\hline WHO III or Gleason $\geq 8$ & $20(16)$ \\
\hline Unknown & $24(19)$ \\
\hline Median (IQR) PSA at diagnosis $(\mathrm{n}=86)$ & $17.8(8.9-38.5)$
\end{tabular}

mean over 200 replications used as the final estimate. Centile based confidence intervals for both the risk curve and the Lorenz curve ${ }^{20}$ were obtained with bootstrap methods.

\section{RESULTS}

Table 1 shows characteristics of the entire cohort at 31 December 2006. A total of 126 men were diagnosed with prostate cancer, of whom 43 either had metastatic disease at diagnosis $(n=13)$, subsequently developed metastases $(n=18)$, or died from prostate cancer without clinical documentation of metastases $(n=12)$. Thirty five men died from prostate cancer. We excluded one case (a man who died from prostate cancer) from the analysis because blood samples were insufficient to measure prostate specific antigen. We also excluded 11 controls (two matched for prostate cancer, five matched for metastases, and four matched for death) with insufficient blood samples. Median times to diagnosis, metastasis, and cancer specific death were 15.3, 15.7, and 15.9 years, respectively. The similarity of these estimates is because only a subset of men diagnosed with cancer went on to develop metastases and these tended to be diagnosed earlier. The imputed median prostate specific antigen concentration for the entire cohort was $1.06 \mathrm{ng} / \mathrm{ml}$ (interquartile range $0.65-1.92$ ), similar to that reported for US men. ${ }^{21}$

Table 2 gives details of the diagnosis in the 126 affected men. Most commonly, prostate cancer was detected during investigation for urinary symptoms $(79 \%)$. No man had cancer detected by screening. Curative treatment was rare, with only one man undergoing radical prostatectomy. Bone scans were not routine for much of the period of the study, and many patients are therefore not classified for metastasis at diagnosis.

Prostate specific antigen at age 60 was associated with risk of prostate cancer diagnosed clinically by
Age at diagnosis (years):

\begin{tabular}{ll}
\hline $61-65$ & $15(12)$ \\
\hline $66-70$ & $19(15)$ \\
\hline $71-75$ & $33(26)$ \\
\hline $76-80$ & $27(21)$ \\
\hline $81-86$ & $32(25)$ \\
\hline
\end{tabular}

Reason for investigation leading to diagnosis $(n=77)^{\star}$ :

\begin{tabular}{lc}
\hline Lower urinary tract symptoms* $^{*}$ & $61(79)$ \\
\hline Haematuria & $5(6)$ \\
\hline Erectile dysfunction* & $3(4)$ \\
\hline Pain & $6(8)$ \\
\hline Metastases (lymph node or bone) & $2(3)$ \\
\hline Fatigue & $1(1)$ \\
\hline Received treatment for prostate cancer (n=115) $+:$ & \\
\hline Received any treatment & $66(57)$ \\
\hline Within six months of diagnosis: & $1(1)$ \\
\hline Radical prostatectomy & $32(28)$ \\
\hline Medical therapy & $14(12)$ \\
\hline Orchidectomy & $5(4)$ \\
\hline Radiation therapy & $18(16)$ \\
\hline After six months of diagnosis: & $6(5)$ \\
\hline Medical treatment & $12(10)$ \\
\hline Orchidectomy
\end{tabular}

$\mathrm{IQR}=$ interquartile range; $\mathrm{PSA}=$ prostate specific antigen.

*1 patient presented with both lower urinary tract symptoms and erectile dysfunction.

†4 patients received both medical therapy and orchidectomy; 1 patient had both radiation therapy and orchidectomy; 1 patient had radiation, medical therapy and orchidectomy.

age 85 (area under the curve $0.76,95 \%$ confidence interval 0.71 to $0.81 ; \mathrm{P}<0.001)$. This association remained for cancers detected more than 20 years after the blood sample (33 cases, $0.69, \mathrm{P}=0.005$ ). Prostate specific antigen was also associated with prostate cancer metastases $(0.86,0.79$ to $0.92 ; \mathrm{P}<0.001)$, and 


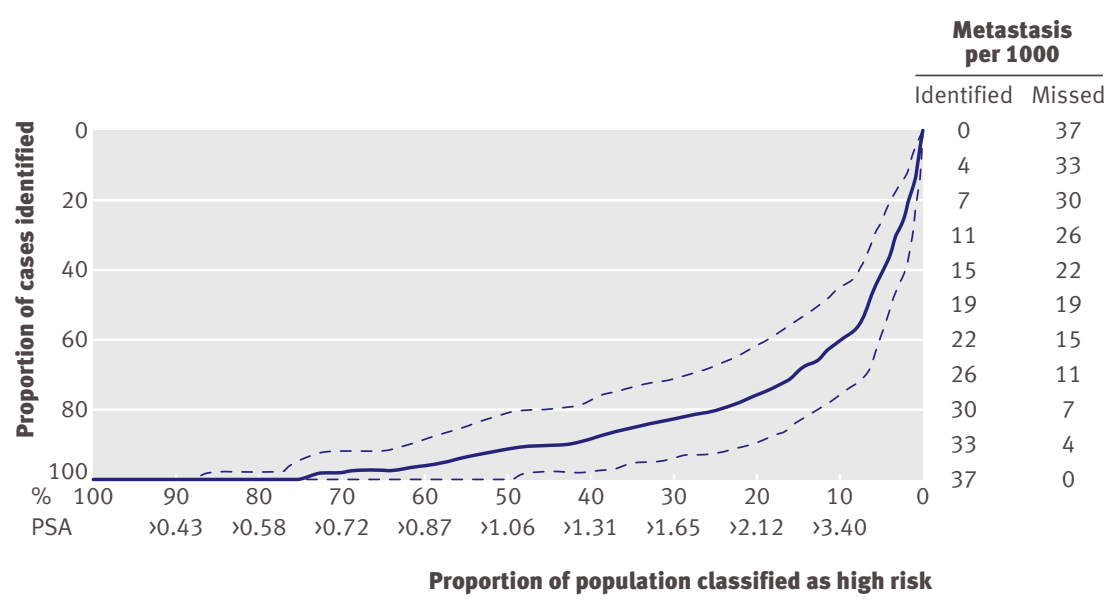

Fig 3 | Lorenz curve for prostate cancer metastasis: $x$ axis shows percentage of population with prostate specific antigen (PSA) above indicated concentrations, hence percentages run from 100 down to 0 ; $y$ axis shows number of events that would be included (or missed) if we consider only men with prostate specific antigen above any given concentration

death from prostate cancer $(0.90,0.84$ to 0.96 ; $\mathrm{P}<0.001)$. Again, these associations remained for events occurring after 20 years $(0.83, \mathrm{P}=0.046$, in 12 patients with metastasis; $0.84, \mathrm{P}=0.051$, in 10 patients who died).

Table 3 gives an initial descriptive analysis of the association between prostate specific antigen and subsequent prostate cancer events after we categorised the data by population quarters of prostate specific antigen concentration. As an example, men with a prostate specific antigen concentration $\geq 2 \mathrm{ng} / \mathrm{ml}$ at age 60 , have, on average, 26 times the odds of dying from prostate cancer than men with a concentration $<2 \mathrm{ng} / \mathrm{ml}$. Table 4 gives predicted risks of a diagnosis of prostate cancer, metastasis, and death by age 85 for population centiles of prostate specific antigen; the association is shown graphically in figure 1, showing strong trends with increasing concentration. If adjustment is made for overdiagnosis, ${ }^{10}$ the relation between prostate specific antigen and subsequent clinically detected cancer is comparable with that reported between prostate specific antigen and biopsy detectable cancer in the US population, ${ }^{4}$ indicating broad applicability of our findings. The risk of a clinically detected prostate cancer rises smoothly with increasing concentration of prostate specific antigen; in contrast, metastases and death from prostate cancer were rare in men with a concentration less than $1 \mathrm{ng} / \mathrm{ml}$ at age 60 , but then rose rapidly as the concentrations increased. As a result, prostate specific antigen concentration at age 60 can predict the probability that a man will die from prostate cancer after a subsequent diagnosis. For example, of 25 men with baseline concentrations of $1-2 \mathrm{ng} / \mathrm{ml}$ who were later diagnosed with prostate cancer, only two $(8 \%)$ died from prostate cancer by the end of the study. In comparison, of 18 men with baseline concentrations of $5-10 \mathrm{ng} / \mathrm{ml}$ who were later diagnosed with prostate cancer, six $(33 \%)$ died from prostate cancer.

Figures 2-4 show Lorenz curves for each event, with cumulative probabilities by population centile shown in table 5. These results can be used to evaluate risk stratification strategies for screening and early detection. It can be seen, for example, that $90 \%$ of metastases and $95 \%$ of deaths occur in men with prostate specific antigen concentrations above the median at age 60 , equivalent to a concentration of about $1 \mathrm{ng} / \mathrm{ml}$. Men with concentrations $\leq 1 \mathrm{ng} / \mathrm{ml}$ had a $0.5 \%$ probability of metastasis by age 85 and a $0.2 \%$ probability of death from prostate cancer. Two men in our cohort had concentrations close to or less than $1 \mathrm{ng} / \mathrm{ml}$ at age 60 and subsequently died from prostate cancer. These deaths occurred at age $84(1.04 \mathrm{ng} / \mathrm{ml}$ at baseline $)$ and 85 $(0.86 \mathrm{ng} / \mathrm{ml}$ at baseline).

Six men in our dataset had prostate specific antigen concentrations of $20 \mathrm{ng} / \mathrm{ml}$ or more, and four of these men died of prostate cancer. These men might have had incurable disease at the time of the blood sample and therefore prostate specific antigen based screening at this age would possibly have made little difference to their survival. In a sensitivity analysis, we excluded these six cases but saw no important influence on our findings: the proportion of deaths from cancer in men in the top quarter of prostate specific antigen remained at $90 \%$. The proportion of deaths occurring in the top quarter was also unaffected if we excluded men dying of prostate cancer within five $(91 \%)$ or $10(89 \%)$ years.

Baseline free prostate specific antigen, free:total prostate specific antigen ratio, and hK2 predicted all three end points. Total prostate specific antigen, however, was the best single marker, and its predictive accuracy was enhanced only by the other kallikrein markers for men with concentrations above the median (table 6).

\section{DISCUSSION}

\section{Overview of findings}

Concentrations of prostate specific antigen at age 60 predict the risk that a man will die from prostate cancer by the age of 85 . The association between prostate spe-

Table $3 \mid$ Conditional logistic regression based on prostate specific antigen (PSA) concentrations at age 60. Categories of PSA are close to quarters of distribution

\begin{tabular}{|c|c|c|c|}
\hline $\begin{array}{l}\text { PSA } \\
(\mathrm{ng} / \mathrm{ml})\end{array}$ & $\begin{array}{c}\text { No (\%) } \\
\text { of cases }\end{array}$ & $\begin{array}{c}\text { No }(\%) \\
\text { of controls }\end{array}$ & $\begin{array}{c}\text { Odds ratio } \\
(95 \% \mathrm{Cl})\end{array}$ \\
\hline \multicolumn{4}{|c|}{ Clinically diagnosed prostate cancer } \\
\hline$<0.65$ & $9(7)$ & $101(27)$ & Reference \\
\hline $0.65-0.99$ & $15(12)$ & $79(21)$ & 2.3 (0.89 to 5.7$)$ \\
\hline $1.00-1.99$ & 24 (19) & $118(32)$ & 2.5 (1.1 to 5.9$)$ \\
\hline$\geq 2.00$ & $77(62)$ & $75(20)$ & 13 (5.7 to 29$)$ \\
\hline \multicolumn{4}{|c|}{ Prostate cancer metastases } \\
\hline$<0.65$ & $0(0)$ & $34(28)$ & \multirow{3}{*}{ Reference } \\
\hline $0.65-0.99$ & $3(7)$ & $19(16)$ & \\
\hline $1.00-1.99$ & $5(12)$ & $36(30)$ & \\
\hline$\geq 2.00$ & $34(81)$ & $32(26)$ & $17(5.2$ to 57$)$ \\
\hline \multicolumn{4}{|c|}{ Death from prostate cancer } \\
\hline$<0.65$ & $0(0)$ & $25(26)$ & \multirow{3}{*}{ Reference } \\
\hline $0.65-0.99$ & $1(3)$ & $15(15)$ & \\
\hline $1.00-1.99$ & $2(6)$ & $32(33)$ & \\
\hline$\geq 2.00$ & $31(91)$ & $26(27)$ & $26(6.2$ to 113$)$ \\
\hline
\end{tabular}


Table $4 \mid$ Risk of clinically diagnosed prostate cancer and death from prostate cancer before age 85 by prostate specific antigen (PSA) concentration at age 60 . Figures are predicted risk (95\% confidence interval)

\begin{tabular}{lcccc} 
Centile & $\begin{array}{c}\text { PSA } \\
\text { (ng/ml* }\end{array}$ & $\begin{array}{c}\text { Clinically diagnosed } \\
\text { prostate cancer }\end{array}$ & $\begin{array}{c}\text { Prostate cancer } \\
\text { metastases }\end{array}$ & $\begin{array}{c}\text { Death from prostate } \\
\text { cancer }\end{array}$ \\
\hline 99 & 14.8 & $60(46$ to 73$)$ & $32(21$ to 44$)$ & $30(19$ to 42$)$ \\
\hline 95 & 5.17 & $39(31$ to 47$)$ & $19(12$ to 25$)$ & $17(11$ to 23$)$ \\
\hline 90 & 3.40 & $28(22$ to 33$)$ & $12(8.3$ to 16$)$ & $11(7.1$ to 15$)$ \\
\hline 75 & 2.12 & $17(14$ to 20$)$ & $6.6(4.6$ to 8.8$)$ & $5.7(3.8$ to 7.7$)$ \\
\hline 67 & 1.92 & $15(13$ to 19$)$ & $5.8(4.0$ to 7.7$)$ & $4.8(3.2$ to 6.6$)$ \\
\hline 50 & 1.50 & $11(8.9$ to 14$)$ & $3.5(2.2$ to 4.9$)$ & $2.7(1.6$ to 3.9$)$ \\
\hline 25 & 1.06 & $7.2(5.4$ to 9.1$)$ & $1.6(0.75$ to 2.5$)$ & $0.9(0.30$ to 1.7$)$ \\
\hline 10 & 0.65 & $4.3(2.4$ to 6.4$)$ & $0.53(0.17$ to 0.97$)$ & $0.28(0.08$ to 0.53$)$ \\
\hline
\end{tabular}

*Imputed to whole population from case-control data.

cific antigen and death from prostate cancer is stronger than the association between prostate specific antigen and cancer detectable at biopsy, ${ }^{4}$, suggesting that prostate specific antigen concentrations are more useful in detecting tumours of greater malignant potential.

Our study has several strengths. Participants were followed to an advanced age, when most had died. The use of archival anticoagulated plasma has been shown to reflect prostate specific antigen concentrations had they been measured contemporaneously. ${ }^{15}$ Few, if any, men in the cohort would have undergone prostate specific antigen screening; we therefore avoided verification bias $^{22}$ and were able to provide estimates for the risk of clinically diagnosed cancer, rather than biopsy detectable cancer, ${ }^{4}$ which might never affect a man before he dies from another cause. All men in the study were the same age-one typical for those currently undergoing screening-ensuring the direct applicability of our findings. The cohort was highly representative of the population, and the large cohort size led to narrow confidence intervals around most of the risk estimates.

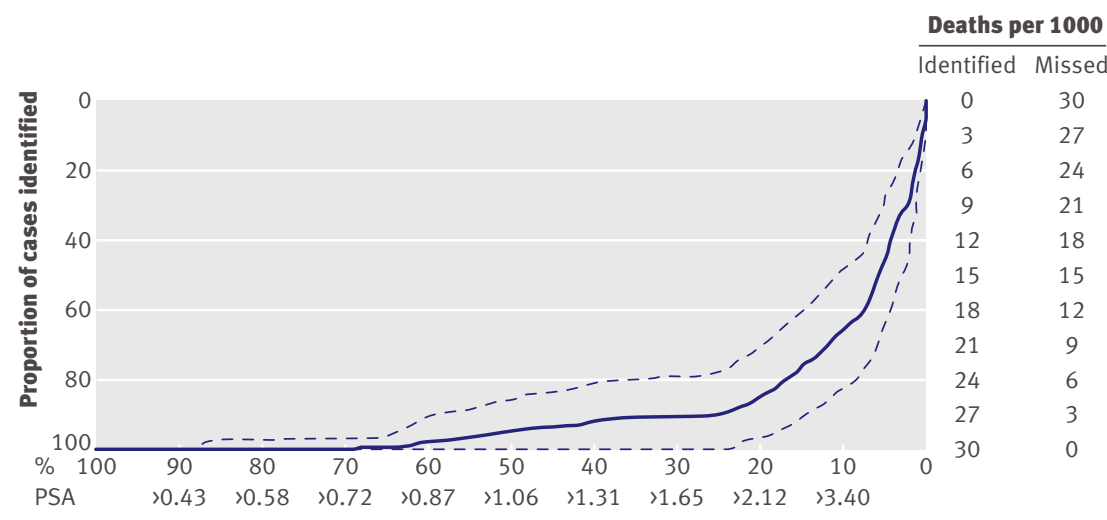

Proportion of population classified as high risk

Fig 4 | Lorenz curve for death from prostate cancer: $x$ axis shows percentage of population with prostate specific antigen (PSA) above indicated concentrations, hence percentages run from 100 down to 0 ; $y$ axis shows number of events that would be included (or missed) if we consider only men with prostate specific antigen above any given concentration
The reason why prostate specific antigen concentrations predict events occurring 25 years subsequently is not entirely clear. There are data suggesting that a significant proportion of men with concentrations above the median, but below conventional biopsy thresholds, have prostate cancer detectable either by biopsy ${ }^{7}$ or pathological analysis of the prostate at autopsy. ${ }^{8}$ Alternatively, such increases in prostate specific antigen might be associated with pre-malignant conditions. Either way, however, the implications are not obvious. Even if our findings are driven by detectable prostate cancers, biopsy would be indicated only if it could be shown that waiting for the prostate specific antigen concentration to rise further would result in a substantial risk of the cancer becoming incurable. It is also unclear whether chemoprevention would be effective only for pre-malignant states, or whether it might also have a cytostatic effect on established cancers. ${ }^{23}$

\section{Comparison with other studies}

Several studies have reported findings that support those presented here. Stenman and coworkers identified 44 cases of prostate cancer in a cohort of over 20000 Finnish men and reported associations between baseline prostate specific antigen and the risk of clinically detected cancer within six to 10 years. ${ }^{24}$ Concentrations were also found to be raised five to six years before diagnosis among the 366 participants in the US Physicians' Health Study who were identified with palpable prostate cancer. ${ }^{25}$ More recently, Holmström and colleagues reported on 540 cases of prostate cancer in a Swedish cohort, with a comparable finding to ours that prostate specific antigen less than $1 \mathrm{ng} / \mathrm{ml}$ "virtually ruled out prostate cancer" during a mean follow-up of seven years. ${ }^{26}$ We have previously reported data from the Malmo cohort showing a strong association between a prostate specific antigen concentration measured at age 44-50 and prostate cancer diagnosed clinically up to 25 years subsequently ${ }^{11}$; the association was strengthened for cancers that were advanced at diagnosis. ${ }^{27}$ Our current data, however, are unique in examining the relation of prostate specific antigen concentrations at the age appropriate for screening with lifetime risk of metastases or death from prostate cancer.

\section{Clinical implications}

Our results have a clear application to early detection and chemoprevention of prostate cancer. Two randomised trials have recently reported the effects of prostate specific antigen screening on death from prostate cancer. The Prostate, Lung, Colorectal, and Ovarian Screening trial (PLCO) in the US did not find an advantage to screening at a median follow-up of seven years, ${ }^{1}$ although important concerns have been raised as to the widespread use of prostate specific antigen testing in the control arm of this trial. ${ }^{28}$ The European Randomised Trial of Screening for Prostate Cancer (ERSPC) reported a 20\% reduction in death from prostate cancer with screening, ${ }^{2}$ though it was estimated that 1410 men needed to be screened to prevent one death. We found that a high proportion of deaths from prostate cancer occur in men with the highest prostate 
Table $5 \mid$ Cumulative proportion (\%) of cases ( $95 \%$ confidence intervals) above centiles of prostate specific antigen (PSA) concentration

\begin{tabular}{lcccc} 
Centile & $\begin{array}{c}\text { PSA } \\
\text { (ng/ml)* }\end{array}$ & $\begin{array}{c}\text { Prostate } \\
\text { cancers }\end{array}$ & $\begin{array}{c}\text { Prostate cancer } \\
\text { metastases }\end{array}$ & $\begin{array}{c}\text { Prostate } \\
\text { cancer } \\
\text { deaths }\end{array}$ \\
\hline 90 & 3.40 & $41(33$ to 50$)$ & $61(46$ to 77$)$ & $66(49$ to 83$)$ \\
\hline 80 & 2.12 & $58(50$ to 66$)$ & $76(61$ to 89$)$ & $85(71$ to 97$)$ \\
\hline 75 & 1.92 & $62(54$ to 70$)$ & $80(68$ to 93$)$ & $90(78$ to $>99)$ \\
\hline 67 & 1.50 & $70(61$ to 78$)$ & $84(72$ to 95$)$ & $91(79$ to $>99)$ \\
\hline 50 & 1.06 & $80(72$ to 87$)$ & $91(81$ to $>99)$ & $95(86$ to $>99)$ \\
\hline 10 & 0.65 & $93(88$ to 97$)$ & $99(94$ to $>99)$ & >99(97 to >99) \\
\hline
\end{tabular}

*Imputed to whole population from case-control data.

specific antigen concentrations: $66 \%$ in the top $10 \%$ $(>3.4 \mathrm{ng} / \mathrm{ml})$ and $95 \%$ in men above the median $(>1$ $\mathrm{ng} / \mathrm{ml}$ ). For men over 60 , focusing screening on those at increased risk - that is, men with concentrations greater than the median at age 60-is likely to shift the ratio of harms to benefits for screening. In response to advocates of screening who might criticise a risk stratification approach as mere cost cutting, we argue that risk stratification would probably lead to increased acceptance for screening among patients. Despite several recommendations in favour of prostate cancer screening, ${ }^{2930}$ currently only half of age appropriate US men undergo regular tests. ${ }^{3}$ Compliance would probably increase among those at high risk if they were informed of their risk status.

Similar considerations apply to chemoprevention. Targeting treatment to men with increased prostate specific antigen concentrations will reduce the medical

Table $6 \mid$ Association between prostate cancer outcomes and total prostate specific antigen (PSA), free PSA, \% free PSA, and kallikrein related peptidase 2 (hK2) at age 60, overall and for men with total PSA above median. Figures are areas under curve $(95 \% \mathrm{Cl})$; the greater the value the better the test

\begin{tabular}{lccc} 
& $\begin{array}{c}\text { Clinically diagnosed } \\
\text { prostate cancer }\end{array}$ & $\begin{array}{c}\text { Prostate cancer } \\
\text { metastases }\end{array}$ & $\begin{array}{c}\text { Death from prostate } \\
\text { cancer }\end{array}$ \\
\hline All men aged 60 & $125 / 373$ & $42 / 121$ & $34 / 98$ \\
\hline No of cases/controls & $0.76(0.71$ to 0.81$)$ & $0.86(0.79$ to 0.93$)$ & $0.90(0.84$ to 0.96$)$ \\
\hline Model: & $0.74(0.69$ to 0.80$)$ & $0.83(0.77$ to 0.91$)$ & $0.88(0.81$ to 0.95$)$ \\
\hline Total PSA & $0.70(0.65$ to 0.75$)$ & $0.78(0.70$ to 0.86$)$ & $0.80(0.71$ to 0.88$)$ \\
\hline Free PSA & $0.69(0.64$ to 0.75$)$ & $0.77(0.64$ to 0.86$)$ & $0.81(0.72$ to 0.90$)$ \\
\hline \% free PSA & $0.76(0.71$ to 0.81$)$ & $0.87(0.81$ to 0.93$)$ & $0.91(0.86$ to 0.97$)$ \\
\hline hK2 & & &
\end{tabular}

Men aged 60 with PSA $\geq 1.0 \mathrm{ng} / \mathrm{ml}$ (median)

\begin{tabular}{llll}
\hline No of cases/controls & $101 / 193$ & $39 / 68$ & $33 / 58$ \\
\hline Model: & & & \\
\hline Total PSA & $0.75(0.69$ to 0.81$)$ & $0.82(0.73$ to 0.91$)$ & $0.85(0.77$ to 0.94$)$ \\
\hline Free PSA & $0.73(0.67$ to 0.79$)$ & $0.79(0.70$ to 0.88$)$ & $0.83(0.74$ to 0.92$)$ \\
\hline \% free PSA & $0.65(0.58$ to 0.71$)$ & $0.73(0.63$ to 0.83$)$ & $0.76(0.65$ to 0.86$)$ \\
\hline hK2 & $0.68(0.62$ to 0.75$)$ & $0.75(0.64$ to 0.85$)$ & $0.77(0.66$ to 0.88$)$ \\
\hline Combination $^{*}$ & $0.74(0.68$ to 0.81$)$ & $0.85(0.76$ to 0.92$)$ & $0.89(0.83$ to 0.96$)$ \\
\hline
\end{tabular}

*Total PSA, free PSA, \% free PSA, and hK2. harms and financial costs associated with chemoprevention. As for screening, we argue that risk stratification would also increase the benefits of chemoprevention: despite recommendations, ${ }^{31}$ few men currently undergo chemoprevention for prostate cancer. ${ }^{32}$ This could change if a subgroup of men were told that they were at high risk of clinically relevant prostate cancer.

With regard to counselling of individual patients, it has been suggested that the prostate specific antigen test is insufficiently sensitive for prostate cancer on the grounds that a substantial proportion of men with low concentrations have prostate cancer on biopsy. ${ }^{47}$ In contrast, our findings suggest that 60 year old men with low concentrations can be reassured that even if they do harbour cancer, it is unlikely to become apparent during their lifetime and even less likely to become life threatening.

None the less, a raised prostate specific antigen is far from being an inevitable harbinger of advanced prostate cancer. For instance, only one in six men at the 95th centile of prostate specific antigen at age $60(5.2$ $\mathrm{ng} / \mathrm{ml}$ ) will die of prostate cancer by age 85 . Hence, while a concentration below the median $(\leq 1 \mathrm{ng} / \mathrm{ml})$ can probably "rule out" subsequent death or metastasis from prostate cancer, higher concentrations indicate only that careful monitoring might be warranted.

\section{Limitations}

Our findings are subject to several important caveats. Firstly, our data are based on a single blood test in 60 year old men without screening. This means that, for men undergoing screening in their $50 \mathrm{~s}$, we probably overestimate the risk of a clinical diagnosis of prostate cancer after the age of 60 . This is because some men would have been diagnosed early with cancer detected at screening and thus be removed from the risk set. That said, a small decrease in risk has little effect for most men because most are at low risk, and there are no practical implications to misclassifications between different levels of reduced risk. Moreover, it is prudent to be conservative with respect to risk. We might have also overestimated the risk of clinically detected prostate cancer because overdetection can occur even in the absence of screening. For example, a man presenting to a urologist with prostate symptoms might have a cancer detected during the clinical investigation that would never have become apparent had the patient not developed concurrent benign disease.

Neither of these considerations would have an important effect on our estimates of death from prostate cancer. Such estimates might, however, be affected by improvements in treatment, such as the use of higher dose radiotherapy. Even so, under the assump tion of an approximately constant relative reduction from improved treatment, changes in treatment are unlikely to have an important effect on estimates of cumulative proportions, such as that $90 \%$ of prostate cancer deaths occur in men in the top quarter of prostate specific antigen concentrations at age 60 . 


\section{WHAT IS KNOWN ON THIS TOPIC}

Prostate specific antigen screening is widely used for the early detection of prostate cancer

Screening is associated with considerable overdiagnosis, and many men need to be screened to save one life

\section{WHAT THIS STUDY ADDS}

A single measure of prostate specific antigen at age 60 is associated with a man's lifetime risk of death from prostate cancer

Most (90\%) of deaths from prostate cancer occur in men in the top quarter of prostate specific antigen concentrations $(>2 \mathrm{ng} / \mathrm{ml})$, though only a minority of such men will develop fatal prostate cancer

Men aged 60 with concentrations $\leq 1 \mathrm{ng} / \mathrm{ml}$ can be told that though they might have cancer, it is unlikely to become life threatening

At least half of men at age 60 can be exempted from further screening and chemoprevention

\section{Further research}

Several questions remain for future research. One is whether these results can be replicated in an independent group. Secondly, it is unclear how well our risk estimates apply to men of other races. Both incidence of and mortality from prostate cancer are higher in African-Americans and lower in Asians than in white people. ${ }^{33}$ Whether there are also racial differences in the relation between prostate specific antigen at age 60 and future risks of prostate cancer metastases and death is a question that can be answered only by further research.

We thank Gun-Britt Eriksson and Mona Hassan Al-Battat for expert assistance with immunoassays, and Janet Novak, at Helix Editing, for her assistance with editing of the manuscript.

Contributors: HL and AJV designed the study. HL and PTS obtained funding. PMN, JM, and AD maintained and supervised the Malmo cohort database and bio-repository. HL and DU supervised biomarker measurements. DU, TB, $A B$, and $A D$ gathered data on patients. AJV and AMC analysed data. HL, AMC, PTS, and AJV helped to interpret the results. AJV and HL wrote the paper. All authors had full access to all of the data (including statistical reports and tables) in the study and can take responsibility for the integrity of the data and the accuracy of the data analysis, and all authors approved the final manuscript. $\mathrm{HL}$ is guarantor. Funding: This work was supported by the National Cancer Institute (grant numbers R21-CA127768-01A1, P50-CA92629); the Swedish Cancer Society (3455); the Swedish Research Council (Medicine) (20095); the Sidney Kimmel Center for Prostate and Urologic Cancers; David H Koch through the Prostate Cancer Foundation; and Fundación Federico SA. The manuscript editing was paid for by internal funds at Memorial SloanKettering Cancer Center. The study sponsors had no role in study design; in the collection, analysis, and interpretation of data; in the writing of the report; or in the decision to submit the article for publication. Competing interests: All authors have completed the Unified Competing Interest form at www.icmje.org/coi_disclosure.pdf (available on request from the corresponding author) and declare that $\mathrm{HL}$ holds patents for free PSA and hK2 assays.

Ethical approval: The study was approved by the ethics committee at Lund University. Consent was not obtained from study participants, but the presented data are anonymised and risk of identification is minimal. Data sharing: A full dataset along with the statistical code used for analysis are available from the authors on request, and from the Swedish national data archive (http://www.ssd.gu.se/en). These data can be used only for replication of the analyses published in this paper or for private study. Express written permission must be sought from the authors for any other data use.

1 Andriole GL, Crawford ED, Grubb RL 3rd, Buys SS, Chia D, Church TR, et al. Mortality results from a randomized prostate-cancer screening trial. N Engl J Med 2009;360:1310-9.
2 Schroder FH, Hugosson J, Roobol MJ, Tammela TL, Ciatto S, Nelen V, et al. Screening and prostate-cancer mortality in a randomized European study. N Engl J Med 2009;360:1320-8.

3 Ross LE, Berkowitz Z, Ekwueme DU. Use of the prostate-specific antigen test among U.S. men: findings from the 2005 National Health Interview Survey. Cancer Epidemiol Biomarkers Prev 2008;17:636-44.

4 Thompson IM, Ankerst DP, Chi C, Goodman PJ, Tangen CM, Lucia MS, et al. Assessing prostate cancer risk: results from the Prostate Cancer Prevention Trial. / Natl Cancer Inst 2006;98:529-34.

5 Hernandez J, Thompson IM. Prostate-specific antigen: a review of the validation of the most commonly used cancer biomarker. Cancer 2004:101:894-904.

6 Schröder F, Kattan MW. The comparability of models for predicting the risk of a positive prostate biopsy with prostate-specific antigen alone: a systematic review. Eur Urol 2008:54:274-90.

7 Thompson IM, Pauler DK, Goodman PJ, Tangen CM, Lucia MS, Parnes HL, et al. Prevalence of prostate cancer among men with a prostate-specific antigen level < or $=4.0 \mathrm{ng}$ per milliliter. $N$ Engl $\mathrm{M}$ Med 2004:350:2239-46.

8 Haas GP, Delongchamps NB, Jones RF, Chandan V, Serio AM, Vickers AJ, et al. Needle biopsies on autopsy prostates: sensitivity of cancer detection based on true prevalence. J Natl Cancer Inst 2007;99:1484-9.

9 Welch HG, Albertsen PC. Prostate cancer diagnosis and treatment after the introduction of prostate-specific antigen screening: 19862005. J Natl Cancer Inst 2009;101:1325-9.

10 Draisma G, Etzioni R, Tsodikov A, Mariotto A, Wever E, Gulati R, et al. Lead time and overdiagnosis in prostate-specific antigen screening: importance of methods and context. / Natl Cancer Inst 2009;101:374-83.

11 Lilja H, Ulmert D, Bjork T, Becker C, Serio AM, Nilsson JA, et al. Longterm prediction of prostate cancer up to 25 years before diagnosis of prostate cancer using prostate kallikreins measured at age 44 to 50 years. J Clin Oncol 2007;25:431-6.

12 Lyssenko V, Jonsson A, Almgren P, Pulizzi N, Isomaa B, Tuomi T, et al. Clinical risk factors, DNA variants, and the development of type 2 diabetes. N Engl J Med 2008;359:2220-32.

13 Adolfsson J, Garmo H, Varenhorst E, Ahlgren G, Ahlstrand C, Andren $\mathrm{O}$, et al. Clinical characteristics and primary treatment of prostate cancer in Sweden between 1996 and 2005. Scand J Urol Nephrol 2007;41:456-77.

14 Sandblom G, Dufmats M, Olsson M, Varenhorst E. Validity of a population-based cancer register in Sweden-an assessment of data reproducibility in the South-East Region Prostate Cancer Register. Scand I Urol Nephrol 2003;37:112-9.

15 Ulmert D, Becker C, Nilsson JA, Piironen T, Bjork T, Hugosson J, et al. Reproducibility and accuracy of measurements of free and total prostate-specific antigen in serum vs plasma after long-term storage at -20 degrees C. Clin Chem 2006;52:235-9.

16 Mitrunen K, Pettersson K, Piironen T, Bjork T, Lilja H, Lovgren T. Duallabel one-step immunoassay for simultaneous measurement of free and total prostate-specific antigen concentrations and ratios in serum. Clin Chem 1995;41:1115-20.

17 Vickers AJ, Cronin AM, Roobol MJ, Savage CJ, Peltola M, Pettersson K, et al. Reducing unnecessary biopsy during prostate cancer screening using a four kallikrein panel: an independent replication. J Clin Oncol 2010;28:2493-98.

18 DeLong ER, DeLong DM, Clarke-Pearson DL. Comparing the areas under two or more correlated receiver operating characteristic curves: a nonparametric approach. Biometrics 1988;44:837-45.

19 Cleveland W. Robust locally weighted regression and smoothing scatterplots. J Am Stat Assoc 1979;74:829-36.

20 Moskowitz CS, Seshan VE, Riedel ER, Begg CB. Estimating the empirical Lorenz curve and Gini coefficient in the presence of error with nested data. Stat Med 2008;27:3191-208.

21 Lacher DA, Thompson TD, Hughes JP, Saraiya M. Total, free, and percent free prostate-specific antigen levels among U.S. men, 200104. Adv Data 2006;379:1-12.

22 Cronin AM, Vickers AJ. Statistical methods to correct for verification bias in diagnostic studies are inadequate when there are few false negatives: a simulation study. BMC Med Res Methodol 2008;8:75.

23 Andriole GL, Bostwick DG, Brawley OW, Gomella LG, Marberger M, Montorsi F, et al. Effect of dutasteride on the risk of prostate cancer. $N$ Engl J Med 2010;362:1192-202.

24 Stenman UH, Hakama M, Knekt P, Aromaa A, Teppo L, Leinonen I. Serum concentrations of prostate specific antigen and its complex with alpha 1-antichymotrypsin before diagnosis of prostate cancer. Lancet 1994;344:1594-8.

25 Gann PH, Hennekens $\mathrm{CH}$, Stampfer MJ. A prospective evaluation of plasma prostate-specific antigen for detection of prostatic cancer. JAMA 1995;273:289-94.

26 Holmstrom B, Johansson M, Bergh A, Stenman UH, Hallmans G, Stattin P. Prostate specific antigen for early detection of prostate cancer: longitudinal study. BMJ 2009;339:b3537. 
27 Ulmert D, Cronin AM, Bjork T, O’Brien MF, Scardino PT, Eastham JA, et al. Prostate-specific antigen at or before age 50 as a predictor of advanced prostate cancer diagnosed up to 25 years later: a casecontrol study. BMC Med 2008;6:6.

28 Catalona WJ. Prostate-cancer screening. N Engl J Med 2009;361:202; author reply 204-5.

29 Greene KL, Albertsen PC, Babaian RJ, Carter HB, Gann PH, Han M, et al. Prostate specific antigen best practice statement: 2009 update. J Urol 2009;182:2232-41.

30 National Comprehensive Cancer Network. Prostate cancer early detection. Clinical practice guidelines in oncology. J Natl Compr Canc Netw 2004;2:190-207.
31 Kramer BS, Hagerty KL, Justman S, Somerfield MR, Albertsen PC, Blot WJ, et al. Use of 5-alpha-reductase inhibitors for prostate cancer chemoprevention: American Society of Clinical Oncology/American Urological Association 2008 Clinical Practice Guideline. J Clin Onco 2009;27:1502-16.

32 Goetzl MA, Holzbeierlein JM. Finasteride as a chemopreventive agent in prostate cancer: impact of the PCPT on urologic practice. Nat Clin Pract Urol 2006;3:422-9.

33 Hsieh K, Albertsen PC. Populations at high risk for prostate cancer. Urol Clin North Am 2003;30:669-76.

Accepted: 28 June 2010 